\section{JURNAL EKONOMI EFEKTIF}

ISSN : $2622-8882$, E-ISSN : 2622-9935

Jurnal Ekonomi Efektif, Vol. 3, No. 2, Januari 2021 @Prodi Manajemen Fakultas Ekonomi Universitas Pamulang

\title{
PENGARUH KEPEMIMPINAN TRANSFORMASIONAL DAN MOTIVASI KERJA TERHADAP KINERJA KARYAWAN
}

\author{
Hendry Susanto \\ Universitas Pamulang, Tangerang Selatan, Banten, Indonesia \\ dosen02571@unpam.ac.id
}

Manuskrip: Sept-2020; Ditinjau: Okt-2020; Diterima: Okt-2020; Online: Jan-2021; Diterbitkan: Jan-2021

\begin{abstract}
ABSTRAK
Tujuan dilaksanakannya penelitian ini adalah untuk mengetahui pengaruh kepemimpinan transformasial dan motivasi kerja terhadap karyawan Universitas Pamulang secara parsial maupun secara simultan. Penelitian ini dilakukan selama 5 bulan yakni dari bulan Januari 2018 sampai dengan bulan Mei 2018, metode yang digunakan adalah dengan menggunakan pendekatan kuantitatif dengan menggunakan pendekatan asosiatif. sampel penelitian terdiri dari karyawan Universitas Pamulang sejumlah 100 orang. Pengumpulan data dengan menggunakan wawancara, kuisioner, dokumentasi dan studi kepustakaan, Sedangkan analisis data menggunakan uji validitas, uji reliabilitas, uji normalitas, uji multikorelasi, uji heteroskedastisitas, regresi linear, koefisien determinasi, dan uji signifikan (uji t dan uji F). hasil penelitian yang didapatkan adalah kepemimpinan transformasional dan motivasi secara bersama-sama berpengaruh positif dan signifikan terhadap kinerja karyawan.
\end{abstract}

Kata Kunci: Kepemimpinan, Transformasional, Motivasi Kerja, Kinerja Karyawan.

\begin{abstract}
The purpose of carrying out this research is to determine the effect of transformational leadership and work motivation on employees of Pamulang University partially or simultaneously. This research was conducted for 5 months, from January 2018 to May 2018, the method used is to use a quantitative approach using an associative approach. The research sample consisted of 100 employees of Pamulang University. Collecting data using interviews, questionnaires, documentation and literature study, while data analysis used validity tests, reliability tests, normality tests, multicorrelation tests, heteroscedasticity tests, linear regression, coefficient of determination, and significant tests ( $t$ test and $F$ test). The research results obtained are transformational leadership and motivation together have a positive and significant effect on employee performance.
\end{abstract}

Keywords: Leadership, Transformational, Work Motivation, Employee Performance. 


\section{PENDAHULUAN}

\section{A. Latar Belakang Masalah}

Sebuah perusahaan dapat dikatakan sukses apabila dalam perkembangannya tidak mengesampingkan hubungan yang baik antara pemimpin dan karyawannya. Hubungan yang harmonis antara pimpinan dan karyawan akan meningkatkan kinerja karyawan untuk meningkatkan dan berkembangnya perusahaan. Universitas Pamulang adalah sebuah perguruan tinggi yang berada di kota Tangerang Selatan dengan jumlah mahasiswa mencapai hampir 90 ribu, membutuhkan pengelolaan manajemen yang baik. Manajemen dan pengelolaan ini membutuhkan dukungan seorang pemimpin yang transformasional untuk meningkatkan kinerja karyawannya. "Untuk menunjang keberhasilan manajemen Kepemimpinan dibutuhkan seorang pemimpin yang dapat melaksanakan tugas dan fungsi manajemen. Seorang pemimpin yang baik harus dapat memberikan motivasi agar dapat mencapai produktivitas kerja dan kepuasan kerja bawahannya'". (Simanjuntak \& Calam, 2012)

Karyawan merasa percaya, kagum, loyal, dan hormat terhadap atasannya sehingga bawahan termotivasi untuk berbuat lebih banyak dari pada apa yang dilakukan dan diharapkannya. Kepemimpinan transformasional pada prinsipnya memotivasi karyawan untuk berbuat lebih baik dari apa yang biasa dilakukan, dengan kata lain dapat meningkatkan kepercayaan atau keyakinan diri bawahan yang akan berpengaruh terhadap peningkatan kerja.

Motivasi atau dorongan untuk bekerja sangat penting dalam penentuan tinggi rendahnya kerja perusahaan. Sukses tidak suatu perusahaan, sangat tergantung dari aktivitas dan kreativitas karyawan Motivasi juga akan mendorong seseorang untuk bekerja lebih baik agar meraih kinerja yang diharapkan, sehingga mendapatkan apa yang menjadi kebutuhannya. Oleh karena itu, motivasi sangat penting dimiliki oleh pemimpin dan karyawan dalam meningkatkan semangat kerja dan kinerja para karyawan. Kinerja karyawan tidak akan terlepas dari peran kepemimpinan yang ada dalam organisasi tersebut. Hal ini dikarenakan kepemimpinan dapat mengarahkan tujuan organisasi, memotivasi prilaku kearah pencapaian tujuan tersebut, dan mampu mendefenisikan budaya organisasi. Dalam kinerja dikenal dengan adanya penilaian kinerja yang digunakan untuk pengukuran kinerja. Penilaian kinerja merupakan suatu proses organisasi dalam menilai kinerja karyawan. penilaian kinerja merupakan evaluasi yang sistematis dari pekerjaan pegawai dan potensi yang dapat dikembangkan.

Jadi pada dasarnya apabila perusahaan ingin meraih kinerja yang optimal sesuai dengan target yang telah ditentukan, maka perusahaan haruslah memberikan motivasi pada karyawan, agar karyawan mau dan rela mencurahkan tenaga dan pikiran yang dimiliki demi pekerjaan. Dalam mencapai tingkat kepuasan kerja yang tinggi pada Universitas Pamulang, perusahaan yang bergerak dalam bidang pendidikan ini, kepemimpinan transformasional sangat berpengaruh terhadap meningkatnya kepuasan kinerja karyawan, motivasi kerja dapat juga berpengaruh terhadap kepuasan kerja.

Dalam perusahaannya Universitas Pamulang selalu senantiasa membina hubungan baik dan harmonis dengan karyawannya, dengan mengarahkan motivasi, menciptakan kepemimpinan yang baik, sehingga para karyawan merasa terpacu untuk bekerja lebih keras agar kinerja yang dicapai juga tinggi. Sehingga Universitas Pamulang memberi penghargaan yang layak kepada karyawan yang berprestasi, juga meningkatkan kompentensi karyawan melalui pengembangan dan peningkatan keahlian serta kemampuan individual karyawan. Untuk mencapai tingkat kepuasan yang tinggi terhadap kinerja karyawan pada Universitas Pamulang di butuhkan sumber daya manusia yang memadai, agar tujuan perusahaan dapat tercapai secara efektif. Jika keberhasilan 
yang dilakukan oleh pimpinan pada Universitas Pamulang dalam memotivasi karyawan melalui kepemimpinan transformasional, pada akhirnya kinerja karyawan berjalan dengan sangat baik, maka dari itu peneliti tertarik untuk melakukan penelitian dengan judul 'Pengaruh Kepemimpinan Transformasional dan Motivasi Kerja Terhadap Kinerja Karyawan pada Universitas Pamulang',

\section{B. Rumusan Masalah}

1. Seberapa besar pengaruh Kepemimpinan Transformasional terhadap Kinerja Karyawan pada Universitas Pamulang?

2. Seberapa besar pengaruh Motivasi Kerja terhadap Kinerja Karyawan pada Universitas Pamulang?

3. Seberapa besar pengaruh Kepemimpinan Transformasional dan Motivasi Kerja terhadap Kinerja Karyawan pada Universitas Pamulang?

\section{Tujuan Penelitian}

1. Untuk mengetahui seberapa besar pengaruh Kepemimpinan Transformasional terhadap Kinerja Karyawan pada Univesitas Pamulang?

2. Untuk Mengetahui seberapa besar pengaruh Motivasi Kerja terhadap Kinerja Karyawan pada Universitas Pamulang?

3. Untuk mengetahui seberapa besar pengaruh Kepemimpinan Transformasional dan Motivasi Kerja terhadap Kinerja Karyawan pada Universitas Pamulang?

\section{METODE PENELITIAN}

\section{Populasi}

Populasi dan sampel penelitian dalam penelitian ini populasi yang akan dipilih adalah 100 karyawan.

\section{Sampel}

sampel penelitian dalam penelitian ini populasi yang akan dipilih adalah 100 karyawan dari seluruhnya berjumlah 133 orang karyawan dengan menggunakan Teknik random sampling.

\section{Jenis Penelitian}

Jenis penelitian yang dipakai adalah asosiatif, dimana tujuannya adalah untuk mengetahui mencari keterhubungan antara variabel $\mathrm{x}$ dan variabel y

\section{Metode Analisis Data}

Dalam menganalisis data digunakan uji instrumen, uji asumsi klasik, regresi, koefisien determinasi dan uji hipotesis.

\section{HASIL PENELITIAN DAN PEMBAHASAN}

\section{Uji Hipotesis}

Tujuan uji hipotesis adalah untuk menguji apakah data dari sampel yang ada sudah cukup kuat untuk menggambarkan populasinya. Uji hipotesis berguna untuk memeriksa atau menguji apakah koefisien regresi yang di dapat signifikan (berbeda nyata). Maksud dari signifikan ini adalah "'suatu nilai koefisien regresi yang secara statistik tidak sama dengan nol, berarti dapat dikatakan tidak cukup bukti untuk menyatakan variabel bebas mempunyai pengaruh terhadap variabel terikat. Untuk itu koefisien regresi harus diuji”(Singgih Santoso, $2010: 79$ ). 


\section{a. Hasil Pengujian Hipotesis Pertama}

Tabel 1

Korelasi Kepemimpinan Transformasional (X1) Terhadap Kinerja Karyawan (Y)

Correlations

\begin{tabular}{|c|c|c|c|}
\hline & & $\begin{array}{c}\text { KINERJA } \\
\text { KARYAWAN }\end{array}$ & $\begin{array}{c}\text { KEPEMIMPINAN } \\
\text { TRANSFORMASIONAL }\end{array}$ \\
\hline \multirow{2}{*}{$\begin{array}{l}\text { Pearson } \\
\text { Correlation }\end{array}$} & KINERJA KARYAWAN & 1.000 & .690 \\
\hline & $\begin{array}{l}\text { KEPEMIMPINAN } \\
\text { TRANSFORMASIONAL }\end{array}$ & .690 & 1.000 \\
\hline Sig. (1-tailed) & $\begin{array}{l}\text { KINERJA KARYAWAN } \\
\text { KEPEMIMPINAN } \\
\text { TRANSFORMASIONAL }\end{array}$ & 然. & .000 \\
\hline $\mathrm{N}$ & $\begin{array}{l}\text { KINERJA KARYAWAN } \\
\text { KEPEMIMPINAN } \\
\text { TRANSFORMASIONAL }\end{array}$ & 100 & $\begin{array}{l}100 \\
100\end{array}$ \\
\hline
\end{tabular}

1) Analisis Regresi Linear Sederhana

"Hasil penelitian ini berhasil mendukung hipotesis $\mathrm{H} 2$ bahwa motivasi kerja berpengaruh positif dan signifikan terhadap kinerja karyawan. Motivasi kerja berpengaruh positif terhadap kinerja karyawan dan merupakan variable independent yang paling dominan'. (Enriko, 2018). Pengujian pertama kepemimpinan transformasional (X1) berpengaruh terhadap kinerja karyawan pada Universitas Pamulang.

Table 2

Hasil Pengolahan Regresi Variabel Kepemimpinan Transformasional (X1) Coefficients $^{\mathrm{a}}$

\begin{tabular}{|c|c|c|c|c|c|c|c|}
\hline \multirow[b]{2}{*}{ Model } & \multicolumn{2}{|c|}{$\begin{array}{c}\text { Unstandardized } \\
\text { Coefficients }\end{array}$} & \multirow{2}{*}{$\begin{array}{c}\text { Standardized } \\
\text { Coefficients } \\
\text { Beta }\end{array}$} & \multirow[b]{2}{*}{$\mathrm{t}$} & \multirow[b]{2}{*}{ Sig. } & \multicolumn{2}{|c|}{$\begin{array}{c}95,0 \% \\
\text { Confidence } \\
\text { Interval for B }\end{array}$} \\
\hline & B & $\begin{array}{l}\text { Std. } \\
\text { Error }\end{array}$ & & & & $\begin{array}{l}\text { Lower } \\
\text { Bound }\end{array}$ & $\begin{array}{l}\text { Upper } \\
\text { Bound }\end{array}$ \\
\hline $1 \quad$ (Constant) & 27,917 & 2,298 & & 12,149 & ,000 & 23,357 & 32,477 \\
\hline $\begin{array}{l}\text { KEPEMIMPINAN } \\
\text { TRANSFORMASIONAL }\end{array}$ & ,459 & ,049 & ,690 & 9,448 &, 000 & ,363 &, 555 \\
\hline
\end{tabular}

a. Dependent Variable: KINERJA KARYAWAN

Berdasarkan tabel diatas maka diperoleh kesamaan regresi linear dalam penelitian ini adalah: $\mathrm{Y}=27,917+0,690 \mathrm{X} 1$. Dapat dijelaskan sebagai berikut:

1. Nilai konstanta sebesar 27,917 berarti bahwa jika variabel X1 tidak ada, maka terdapat Y sebesar 27,917

2. Nilai 0,690 berarti apabila konstanta tetap dan tidak ada perubahan pada variabel lain, maka setiap perubahan satu unit pada variabel X1 akan berakibat terjadinya perubahan pada Y sebesar 0,690

2) Analisis Koefisien Determinasi (R-Square)

' 'Koefisien determinasi (R2) mengukur seberapa besar pengaruh variabel kepemimpinan transformasional secara keseluruhan terhadap naik turunnya variasi nilai variabel kinerja karyawan”. (Enriko, 2018). 
Tabel 3

Koefisien Derterminasi Hipotesis Pertama Model Summaryb

\begin{tabular}{|l|c|c|c|c|}
\hline Model & $\mathrm{R}$ & $\mathrm{R}$ Square & Adjusted R Square & $\begin{array}{c}\text { Std. Error of the } \\
\text { Estimate }\end{array}$ \\
\hline 1 & $.690^{\mathrm{a}}$ &, 477 &, 471 & 2,047 \\
\hline
\end{tabular}

a. Predictors: (Constant), KEPEMIMPINAN

TRANSFORMASIONAL

b. Dependent Variable: KINERJA KARYAWAN

Berdasarkan tabel diatas diperoleh nilai R-Square (koefisien determinasi) sebesar 0,471 maka dapat disimpulkan bahwa variabel kepemimpinan transformasional (X1) berpengaruh terhadap variabel kinerja karyawan (Y) sebesar $47,1 \%$ sedangkan sisanya $56,9 \%$ dipengaruhi faktor lain

3) Uji Parsial (uji t)

Pengujian uji t dilakukan untuk mengetahui pengaruh "kepemimpinan transformasional (X1) secara parsial (sendiri) berpengaruh signifikan terhadap kinerja karyawan (Y).

Tabel 4

Hasil Uji t Parsial Hipotesis Pertama

Coefficients $^{\mathrm{a}}$

\begin{tabular}{|c|c|c|c|c|c|c|c|}
\hline \multirow[b]{2}{*}{ Model } & \multicolumn{2}{|c|}{$\begin{array}{l}\text { Unstandardize } \\
\text { d Coefficients }\end{array}$} & \multirow{2}{*}{$\begin{array}{c}\text { Standardized } \\
\text { Coefficients } \\
\text { Beta } \\
\end{array}$} & \multirow[b]{2}{*}{$\mathrm{t}$} & \multirow[b]{2}{*}{ Sig. } & \multicolumn{2}{|c|}{$\begin{array}{l}95,0 \% \text { Confidence } \\
\text { Interval for B }\end{array}$} \\
\hline & B & $\begin{array}{l}\text { Std. } \\
\text { Error }\end{array}$ & & & & $\begin{array}{l}\text { Lower } \\
\text { Bound }\end{array}$ & $\begin{array}{l}\text { Upper } \\
\text { Bound }\end{array}$ \\
\hline $\begin{array}{ll}1 & \text { (Constant) } \\
& \text { KEPEMIMPINAN }\end{array}$ & 27,917 & 2,298 & & 12,149 & ,000 & 23,357 & 32,477 \\
\hline $\begin{array}{l}\text { TRANSFORMASI } \\
\text { ONAL }\end{array}$ & 459 & ,049 & 690, & 9,448 & ,000 & ,363 & ,555 \\
\hline
\end{tabular}

a. Dependent Variable: KINERJA KARYAWAN

Berdasarkan tabel diatas diperoleh nilai thitung $=9,448>2,626$ atau (thitung $>$ ttabel), hal tersebut juga diperkuat dengan signifikan $0,000<0,05$. Dengan demikian Ho ditolak dan Ha diterima. Artinya terdapat pengaruh positif dan signifikan secara parsial antara Kepemimpinan Transformasional (X1) terhadap Kinerja Karyawan (Y)

\section{b. Hasil Pengujian Hipotesis Kedua}

Pengaruh Motivasi Kerja Terhadap Kinerja Karyawan (X2 ke- Y) Pengolahan menggunakan program SPSS 23, variabel motivasi kerja (X2) terhadap variabel kinerja karyawan (Y) adalah :

Tabel 5

Korelasi Motivasi Kerja (X2) Terhadap Kinerja Karyawan (Y)

\begin{tabular}{|c|c|c|c|}
\hline \multicolumn{4}{|c|}{ Correlations } \\
\hline & & KINERJA KARYAWAN & MOTIVASI KERJA \\
\hline \multirow[t]{2}{*}{ Pearson Correlation } & KINERJA KARYAWAN & 1.000 & .875 \\
\hline & MOTIVASI KERJA & .875 & 1.000 \\
\hline \multirow[t]{2}{*}{ Sig. (1-tailed) } & KINERJA KARYAWAN & 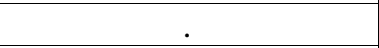 & .000 \\
\hline & MOTIVASI KERJA & .000 &. \\
\hline \multirow[t]{2}{*}{$\mathrm{N}$} & KINERJA KARYAWAN & 100 & 100 \\
\hline & MOTIVASI KERJA & 100 & 100 \\
\hline
\end{tabular}

Korelasi antara motivasi kerja (X2) dan kinerja karyawan (Y) adalah Terdapat 
hubungan yang positif sebesar 0,875 antara variabel motivasi kerja (X2) dengan kinerja karyawan (Y) pada Universitas Pamulang.

1) Analisis Regresi Linear Sederhana

Pengujian kedua motivasi kerja (X1) berpengaruh terhadap kinerja karyawan pada Universitas Pamulang.

Tabel 6

Hasil Pengolahan Regresi "Variabel Motivasi Kerja (X2)

Coefficients $^{\mathrm{a}}$

\begin{tabular}{|c|c|c|c|c|c|c|c|}
\hline \multirow[b]{2}{*}{ Model } & \multicolumn{2}{|c|}{$\begin{array}{l}\text { Unstandardized } \\
\text { Coefficients }\end{array}$} & \multirow{2}{*}{$\begin{array}{c}\text { Standardized } \\
\text { Coefficients } \\
\text { Beta } \\
\end{array}$} & \multirow[t]{2}{*}{$\mathrm{t}$} & \multirow[t]{2}{*}{ Sig. } & \multicolumn{2}{|c|}{$\begin{array}{l}95,0 \% \text { Confidence } \\
\text { Interval for B }\end{array}$} \\
\hline & $\mathrm{B}$ & $\begin{array}{l}\text { Std. } \\
\text { Error }\end{array}$ & & & & $\begin{array}{l}\text { Lower } \\
\text { Bound }\end{array}$ & $\begin{array}{l}\text { Upper } \\
\text { Bound }\end{array}$ \\
\hline $1 \quad$ (Constant) & 12,326 & 2,081 & & 5,922 & ,000 & 8,196 & 16,457 \\
\hline $\begin{array}{l}\text { MOTIVASI } \\
\text { KERJA }\end{array}$ & ,611 & ,034 & ,875 & 17,917 & ,000 &, 543 & 679 \\
\hline
\end{tabular}

a. Dependent Variable: Kinerja Karyawan

Berdasarkan tabel diatas maka diperoleh kesamaan regresi linear dalam penelitian ini adalah: $\mathrm{Y}=12,326+0,875 \mathrm{X} 2$. Dapat dijelaskan sebagai berikut:

a) Nilai konstanta sebesar 12,326 berarti bahwa jika variabel $\mathrm{X} 2$ tidak ada, maka terdapat Y sebesar 12,326

b) Nilai 0,875 berarti apabila konstanta tetap dan tidak ada perubahan pada variabel lain, maka setiap perubahan satu unit pada variabel X2 akan berakibat terjadinya perubahan pada Y sebesar 0,875

2) Analisis Koefisien Determinasi (R-Square)

Koefisien determinasi (R2) mengukur seberapa besar pengaruh variabel motivasi kerja secara keseluruhan terhadap naik turunnya variasi nilai variabel kinerja karyawan.

Tabel 7

Koefisien Derterminasi Hipotesis Kedua Model Summary ${ }^{b}$

\begin{tabular}{|l|r|r|r|r|}
\hline & R & R Square & $\begin{array}{c}\text { Adjusted R } \\
\text { Square }\end{array}$ & $\begin{array}{c}\text { Std. Error of the } \\
\text { Estimate }\end{array}$ \\
\hline 1 & $.875^{\mathrm{a}}$ &, 766 &, 764 & 1,369 \\
\hline
\end{tabular}

a. Predictors: (Constant), Motivasi Kerja

b. Dependent Variable: Kinerja Karyawan

Berdasarkan tabel diatas diperoleh nilai R-Square (koefisien determinasi) sebesar 0,764 maka dapat disimpulkan bahwa variabel motivasi kerja (X2) berpengaruh terhadap variabel kinerja karyawan (Y) sebesar 76,4\% sedangkan sisanya $23,6 \%$ dipengaruhi faktor lain.

3) Uji Parsial (uji t)

untuk mengetahui apakah variabel motivasi kerja (X2) secara parsial (sendiri) berpengaruh signifikan terhadap kinerja karyawan (Y).

Tabel 8

Hasil Uji t Parsial Hipotesis Kedua

Coefficients $^{\text {a }}$

\begin{tabular}{|l|c|c|c|c|c|c|c|}
\hline \multirow{4}{*}{ Model } & \multicolumn{2}{|c|}{$\begin{array}{c}\text { Unstandardized } \\
\text { Coefficients }\end{array}$} & $\begin{array}{c}\text { Standardized } \\
\text { Coefficients }\end{array}$ & t & Sig. & \multicolumn{2}{|c|}{$\begin{array}{c}\text { 95,0\% Confidence } \\
\text { Interval for B }\end{array}$} \\
\cline { 2 - 7 } & B & $\begin{array}{c}\text { Std. } \\
\text { Error }\end{array}$ & Beta & & & $\begin{array}{c}\text { Lower } \\
\text { Bound }\end{array}$ & $\begin{array}{c}\text { Upper } \\
\text { Bound }\end{array}$ \\
\hline
\end{tabular}




\begin{tabular}{|l|l|r|r|r|r|r|r|r|}
\hline 1 & (Constant) & 12,326 & 2,081 & & 5,922 &, 000 & 8,196 & 16,457 \\
\cline { 2 - 8 } & $\begin{array}{l}\text { MOTIVASI } \\
\text { KERJA }\end{array}$ &, 611 &, 034 &, 875 & 17,917 &, 000 &, 543 &, 679 \\
\hline
\end{tabular}

Berdasarkan tabel diatas diperoleh nilai thitung $=17,917>2,626$ atau (thitung > ttabel), hal tersebut juga diperkuat dengan signifikan 0,000 $<0,05$. Dengan demikian" Ho ditolak dan Ha diterima. Artinya terdapat pengaruh positif dan signifikan secara parsial antara Motivasi Kerja (X2) terhadap Kinerja Karyawan (Y).

\section{c. Hasil Pengujian Hipotesis ketiga}

Pengaruh Kepemimpinan Transformasional dan "Motivasi Kerja Terhadap Kinerja Karyawan (X1 dan X2 ke-Y). Pengolahan menggunakan program SPSS 23, variabel kepemimpinan transformasional dan motivasi kerja (X1 dan X2) terhadap variabel kinerja karyawan (Y) adalah:

1) Analisis Regresi Linear Berganda

Pengujian hipotesis ketiga menunjukkan bahwa kepemimpinan transformasional dan motivasi kerja secara simultan berpengaruh terhadap kinerja karyawan pada Universitas Pamulang.

Tabel 8

Hasil Pengolahan Regresi Berganda Variabel X1 dan X2

Coefficients $^{\mathbf{a}}$

\begin{tabular}{|c|c|c|c|c|c|}
\hline \multirow[b]{2}{*}{ Model } & \multicolumn{2}{|c|}{$\begin{array}{l}\text { Unstandardized } \\
\text { Coefficients }\end{array}$} & \multirow{2}{*}{$\begin{array}{c}\text { Standardized } \\
\text { Coefficients } \\
\text { Beta } \\
\end{array}$} & \multirow[b]{2}{*}{$\mathrm{t}$} & \multirow[b]{2}{*}{ Sig. } \\
\hline & B & $\begin{array}{l}\text { Std. } \\
\text { Error }\end{array}$ & & & \\
\hline $\begin{array}{ll}1 & (\text { Constant })\end{array}$ & 12,356 & 2,097 & & $\overline{5,891}$ &, 000 \\
\hline $\begin{array}{l}\text { KEPEMIMPINAN } \\
\text { TRANSFORMASIONAL }\end{array}$ & 010 &, 052 &, 015 & ,193 & ,848 \\
\hline MOTIVASI KERJA & ,603 & ,055 & ,863 & 10,961 & ,000 \\
\hline
\end{tabular}

a. Dependent Variable: Kinerja Karyawan

Berdasarkan hasil perhitungan regresi pada tabel diatas, maka dapat diperoleh persamaan regresinya $Y=12,356+0,015 X_{1}+0,863 X_{2}$.

2) Analisis Koefisien Determinasi (R-Square)

Nilai koefisien (R2) digunakan untuk mengukur besarnya pengaruh variabel kepemimpinan transformasional dan motivasi kerja terhadap kinerja karyawan Universitas Pamulang.

Tabel 9

Koefisien Determinasi Hipotesis Ketiga Model Summary ${ }^{\mathrm{b}}$

\begin{tabular}{|l|c|c|c|c|c|c|}
\hline & & & & & \multicolumn{2}{|c|}{ Change Statistics } \\
\cline { 6 - 7 } Model & $\mathrm{R}$ & $\mathrm{R}$ Square & $\begin{array}{c}\text { Adjusted R } \\
\text { Square }\end{array}$ & $\begin{array}{c}\text { Std. Error of the } \\
\text { Estimate }\end{array}$ & $\begin{array}{c}\text { R Square } \\
\text { Change }\end{array}$ & F Change \\
\hline 1 & $.875^{\mathrm{a}}$ &, 766 &, 761 & 1,375 &, 766 & 158,954 \\
\hline
\end{tabular}

a. Predictors: (Constant),Kepemimpinan Transformasional, Motivasi Kerja

b. Dependent Variable: Kinerja Karyawan

Berdasarkan tabel diatas, diperoleh nilai R-Square (koefisien determinasi) sebesar 0,761 maka dapat disimpulkan bahwa variabel kepemimpinan transformasional dan motivasi kerja berpengaruh terhadap variabel kinerja karyawan sebesar 76,1\% sedangkan sisanya 23,9\% dipengaruhi faktor lain. 
3) Uji Simultan (Uji F)

Tabel 10

Hasil Uji F Simultan hipotesis ketiga

ANOVA ${ }^{\mathrm{a}}$

\begin{tabular}{|l|c|c|c|c|c|}
\hline Model & Sum of Squares & df & Mean Square & F & Sig. \\
\hline Regression & 601.355 & 2 & 300.677 & 158.954 & $.000^{\mathrm{b}}$ \\
Residual & 183.485 & 97 & 1.892 & & \\
Total & 784.840 & 99 & & & \\
\hline
\end{tabular}

a. Dependent Variable: Kinerja Karyawan

b. Predictors: (Constant), Motivasi Kerja, Kepemimpinan Transformasional

Berdasarkan tabel diatas diperoleh nilai Fhitung $=158,954>3,09$ atau (Fhitung > Ftabel), hal tersebut juga diperkuat dengan signifikan 0,000 $<0,05$. Dengan demikian Ho ditolak dan Ha diterima. 'Artinya terdapat pengaruh positif dan signifikan secara simultan antara Kepemimpinan Transformasional dan Motivasi Kerja terhadap kinerja karyawan”.(Iii et al., 2017).

\section{PEMBAHASAN HASIL PENELITIAN}

\section{Pengaruh antara Kepemimpinan Transformasional terhadap Kinerja Karyawan}

Hasil penelitian yang diperoleh berdasarkan data diatas dapat "diketahui adanya pengaruh positif gaya kepemimpinan transformasional terlihat persentasi responden yang menjawab sangat setuju sebanyak $17,4 \%$. Yang menjawab setuju sebanyak $62,5 \%$. Yang menjawab ragu-ragu sebanyak 15,58\%. Yang menjawab tidak setuju 4,58\%. Ini menunjukkan bahwa pendapat responden tentang kepemimpinan transformasional sudah baik, tetapi masih harus lebih ditingkatkan lagi agar kinerja karyawan semakin berjalan dengan sangat baik.

Berdasarkan nilai R-Square (koefisien determinasi) dapat diketahui pengaruh kepemimpinan transformasional terhadap kinerja karyawan sebesar 0,471 atau sebesar 47,1\%. Maka dapat disimpulkan bahwa jika variabel kepemimpinan transformasional tinggi, maka berpengaruh terhadap variabel kinerja karyawan sebesar 47,1\% sedangkan sisanya 56,9\% dipengaruhi oleh faktor lain. Pengujian hipotesis diperoleh nilai thitung $=$ 9,448 > 2,626 (thitung > ttabel). Hal itu diperkuat dengan signifikan 0,000 $<0,05$. Dengan demikian Ho di tolak dan Ha diterima. Artinya kepemimpinan transformasional berpengaruh terhadap kinerja karyawan.

Persamaan regresi linear pada variabel kepemimpinan transformasional terhadap variabel kinerja adalah: $\mathrm{Y}=27,971+0,690 \mathrm{X} 1$. Dapat dijelaskan bahwa nilai konstanta sebesar 27,917 berarti jika variabel X1 tidak ada, maka terdapat Y sebesar 27,917. Dan nilai 0,690 berarti apabila konstanta tetap dan tidak ada perubahan pada variabel lain, maka setiap perubahan satu unit pada variabel X1 akan berakibat terjadi perubahan pada Y sebesar 0,690.

Secara keseluruhan dapat disimpulkan bahwa kepemimpinan transformasional berpengaruh positif dan signifikan secara parsial terhadap kinerja karyawan.

Pengaruh kepemimpinan transformasional (X1) terhadap kinerja karyawan (Y) menunjukkan arah positif, artinya semakin tinggi kepemimpinan transformasional maka semakin tinggi kinerja karyawan. Dalam hal ini kepemimpinan transformasional di Universitas Pamulang berpengaruh positif terhadap kinerja karyawan. Semakin tinggi kepemimpinan transformasional maka semakin tinggi kinerja karyawan.

Hasil dalam penelitian ini sejalan dengan hasil penelitian yang dilakukan oleh Yoshi Tania (2017) yang menemukan bahwa kepemimpinan transformasional berpengaruh signifikan terhadap kinerja. Senada pula dengan Ahmad Calam dan Friskha 
Dora (2015) yang menemukan bahwa ' $k$ epemimpinan transformasional berpengaruh positif signifikan terhadap kinerja"(Hope \& Ca, 2016).

\section{Pengaruh antara Motivasi Kerja terhadap Kinerja Karyawan}

Hasil penelitian ini menunjukkan bahwa motivasi kerja berpengaruh positif dan signifikan terhadap kinerja. "Hasil ini memiliki hasil yang sama dengan penelitian Tanuwibowo dan Setiawan (2015) yang menyatakan bahwa motivasi kerja berpengaruh terhadap kinerja karyawan. Karyawan yang memiliki motivasi kerja yang tinggi maka mereka akan memiliki dorongan untuk menggunakan seluruh kemampuannya untuk bekerja. Kinman (2001) mengatakan bahwa uang atau umpan balik merupakan salah satu faktor ektrinsik yang mempengaruhi motivasi seseorang sehingga memiliki tujuan yang jelas guna meningkatkan kinerjanya''(Hope \& $\mathrm{Ca}, 2016)$. Pada motivasi kerja responden yang menjawab sangat setuju sebesar $16,14 \%$. Yang menjawab setuju sebesar $4,73 \%$. Yang menjawab ragu-ragu sebanyak $0,73 \%$. Yang menjawab tidak setuju sebanyak $0,07 \%$. Ini menunjukkan bahwa pendapat responden tentang variabel motivasi kerja terhadap variabel kinerja karyawan sudah berjalan baik.

Berdasarkan R-Square (koefisien determinasi) dapat diketahui pengaruh motivasi kerja terhadap kinerja karyawan sebesar 0,764 atau sebesar 76,4\%, maka dapat disimpulkan bahwa variabel motivasi kerja berpengaruh terhadap kinerja karyawan sebesar 76,4\% sedangkan sisanya sebesar $23,6 \%$ dipengaruhi oleh faktor lain. Pengujian hipotesis diperoleh nilai thitung $=17,917>2,626$ (thitung $>$ ttabel). Hal itu diperkuat dengan signifikan 0,000 $<0,05$. Dengan demikian Ho ditolak dan Ha diterima. Artinya motivasi kerja berpengaruh terhadap kinerja karyawan.

Persamaan regresi linear pada variabel motivasi kerja terhadap variabel kinerja karyawan adalah: $\mathrm{Y}=12,326+0,875 \mathrm{X} 2$. Dapat dijelaskan bahwa nilai konstanta sebesar 12,326 berarti jika variabel X2 tidak ada maka terdapat Y sebesar 12,2326. Dan nilai 0,875 berarti apabila konstanta tetap dan tidak ada perubahan pada variabel lain, maka setiap perubahan satu unit pada variabel $\mathrm{X} 2$ akan berakibat terjadinya perubahan pada $\mathrm{Y}$ sebesar 0,875 .

Secara keseluruhan dapat disimpulkan bahwa motivasi kerja berpengaruh positif dan signifikan secara parsial terhadap kinerja karyawan.

Hasil penelitian membuktikan bahwa motivasi kerja berdampak pada peningkatan kinerja karyawan. Motivasi kerja adalah kondisi yang berpengaruh membangkitkan, mengarahkan dan memelihara perilaku yang berhubungan dengan lingkungan kerja. Untuk mengetahui keberhasilan kinerja perlu dilakukan evaluasi atau penilaian kinerja dengan berpedoman pada parameter dan indicator yang ditetapkan yang diukur secara efektif dan efisien seperti produktivitasnya. Sedangkan evaluasi kinerja melalui perilaku dilakukan dengan teman sekerja atau mengamati tindakan seseorang dalam menjalankan perintah atau tugas yang diberikan, cara mengkomunikasikan tugas dan pekerjaan dengan orang lain.

Hasil dalam penelitian ini mendukung hasil penelitian yang dilakukan oleh Yoshi Tania (2017) dimana motivasi berpengaruh signifikan terhadap kinerja. Demikian juga dengan penelitian Ahmad Calam dan Friskha Dora (2015) yang menemukan bahwa motivasi berpengaruh signifikan secara positif terhadap kinerja.

\section{Pengaruh antara Kepemimpinan Transformasional dan Motivasi Kerja terhadap Kinerja Karyawan}

Berdasarkan hasil R-Square (koefisien determinasi) variabel kepemimpinan transformasional dan variabel motivasi kerja berpengaruh terhadap variabel kinerja 
karyawan sebesar 0,761 atau $76,1 \%$ sedangkan sisanya $23,9 \%$ dipengaruhi oleh faktor lain.

Pengujian hipotesis diperoleh nilai Fhitung $=158,954>3,09$ (Fhitung $>$ Ftabel). Hal ini diperkuat dengan signifikan $0,000<0,05$. Dengan demikian Ho ditolak Ha diterima. Artinya terdapat pengaruh positif dan signifikan secara simultan antara kepemimpinan transformasional dan motivasi kerja terhadap kinerja karyawan.

Persamaan regresi berganda variabel kepemimpinan transformasional dan variabel motivasi kerja berpengaruh positif terhadap variabel kinerja karyawan. Diperoleh persamaan regresi $\mathrm{Y}=12,356+0,015 \mathrm{X} 1+0,863 \mathrm{X} 2$. Yaitu jika nilai konstanta 12,356 diartikan bahwa tanpa variabel kepemimpinan transformasional dan motivasi kerja, besarnya nilai kinerja karyawan tetap, maka terbentuk sebesar 12,356. Jika variabel kepemimpinan transformasional dengan nilai koefisien sebesar 0,015 meningkat dan variabel motivasi kerja tetap, maka kinerja karyawan akan meningkat sebesar 0,015. Nilai koefisien 0,863 pada variabel motivasi kerja terhadap kinerja karyawan, artinya jika variabel motivasi kerja meningkat dan kepemimpinan transformasional tetap, maka kinerja karyawan akan meningkat sebesar 0,863.

Pengaruh kepemimpinan transformasional dan motivasi kerja terhadap kinerja karyawan dapat dikatakan sangat besar, dimana hal ini terbukti dari besarnya nilai korelasi antara kepemimpinan transformasional dan motivasi kerja dengan kinerja karyawan yang menunjukkan angka yang berkisar antara 0.8 samapi 1. Seorang karyawan dengan kepemimpinan transformasional yang baik dan mempunyai motivasi yang tinggi akan memberikan kontribusi positif terhadap nilai kinerjanya, namun jika salah satu atau bahkan kedua faktor tersebut bernilai negatif maka akan mempengaruhi nilai kinerja seseorang.

Hasil penelitian ini mendukung hasil penelitian yang dilakukan oleh Yoshi Tania (2017) dimana kepemimpinan transformasional dan motivasi kerja sangat berpengaruh terhadap kinerja karyawan. Demikian juga dengan penelitian Ahmad Calam dan Friskha Dora (2015) yang menemukan bahwa kepemimpinan transformasional dan motivasi kerja berpengaruh signifikan secara positif terhadap kinerja karyawan.

\section{PENUTUP}

\section{Kesimpulan}

a. Kepemimpinan transformasional mempunyai pengaruh yang positif dan signifikan terhadap kinerja karyawan. Pengujian hipotesis diperoleh nilai thitung $=9,448>2,626$ (thitung $>$ ttabel). Hal itu diperkuat dengan signifikan $0,000<0,05$. Dengan demikian Ho di tolak dan Hal diterima. Artinya kepemimpinan transformasional berpengaruh terhadap kinerja karyawan. Persamaan regresi linearnya adalah: $\mathrm{Y}=27,971+$ $0,690 X 1$.

b. Motivasi kerja berpengaruh positif dan signifikan terhadap kinerja. Pengujian hipotesis diperoleh nilai thitung $=17,917>2,626$ (thitung $>$ ttabel). Hal itu diperkuat dengan signifikan 0,000 $<0,05$. Dengan demikian Ho ditolak dan Ha2 diterima. Artinya motivasi kerja berpengaruh terhadap kinerja karyawan. Persamaan regresi linearnya adalah: $\mathrm{Y}=12,326+0,875 \mathrm{X} 2$.

c. Kepemimpinan transformasional dan motivasi kerja secara simultan berpengaruh positif dan signifikan terhadap kinerja karyawan. Pengujian hipotesis diperoleh nilai Fhitung $=158,954>3,09$ (Fhitung $>$ Ftabel). Hal ini diperkuat dengan signifikan $0,000<0,05$. Dengan demikian Ho ditolak Ha3 diterima. Artinya terdapat pengaruh positif dan signifikan secara simultan antara kepemimpinan transformasional dan motivasi kerja terhadap kinerja karyawan. Diperoleh persamaan regresi berganda 
adalah: $\mathrm{Y}=12,356+0,015 \mathrm{X} 1+0,863 \mathrm{X} 2$

\section{Saran}

a. Motivasi inspiratif dan perhatian individu yang diberikan pemimpin belum maksimal dan masih kurang memuaskan terutama dalam membangkitkan kepercayaan diri karyawan dan kesulitan serta keluhan karyawan. Sebaiknya dalam hal ini harus di tingkatkan agar karyawan termotivasi dalam bekerja.

b. Perlengkapan kesehatan sebaiknya ditambah agar karyawan merasa aman jika sakit yang tidak terlalu berat. Pimpinan juga perlu memberikan penghargaan kepada karyawan yang berprestasi jika mampu menyelesaikan pekerjaan dengan baik dan tepat waktu, yang pada akhirnya karyawanpun akan termotivasi untuk lebih disiplin dalam bekerja.

c. Inisiatif karyawan harus lebih digali supaya dalam melakukan pekerjaan dengan cara yang berbeda tidak menyimpang dengan tanggung jawab terhadap pekerjaan serta karyawan harus lebih teliti dalam menyelesaikan pekerjaan agar hasil yang dicapai sesuai dengan keinginan lembaga.

\section{DAFTAR PUSTAKA}

Akbar, I. R., \& Wiguna, M. (2020). Hubungan Motivasi Terhadap Prestasi Kerja Guru Pada SMK YAPIA Parung, Kab. Bogor. JENIUS (Jurnal Ilmiah Manajemen Sumber Daya Manusia), 4(1), 61-69.

Enriko, F. (2018). "Pengaruh Kepemimpinan Transformasional, Disiplin dan Motivasi Kerja terhadap Kinerja Guru". Jurnal Pembangunan Nagari, 3(2), 39. https://doi.org/10.30559/jpn.v3i2.102

Hope, R., \& Ca, B. (2016). No 主観的健康感を中心とした在宅高齢者における健康 関連指標に関する共分散構造分析Title. 1-10.

Iii, B. A. B., Jenis, A., \& Penelitian, P. (2017). Sugiyono, Metode Penelitian Pendidikan (Pendekatan kuantitatif, Kualitatif dan R\&D), (Bandung :Alfabeta, 2012),hlm. 141 53. 53-71.

Morgan. (2019). 済無No Title No Title. Journal of Chemical Information and Modeling, 53(9), 1689-1699. https://doi.org/10.1017/CBO9781107415324.004

Praditya Maha Putra, K. A., \& Sudibya, I. G. A. (2019). Pengaruh Kepemimpinan Transformasional Terhadap Motivasi Kerja Dan Kinerja Karyawan. E-Jurnal $\begin{array}{llll}\text { Manajemen Universitas } & \text { Udayana, } & 8618 .\end{array}$ https://doi.org/10.24843/ejmunud.2019.v08.i06.p12

Sarwani, S., Akbar, I. R., Handoko, A. L., \& Ilham, D. (2020). Pengaruh Pelatihan dan Motivasi terhadap Produktivitas Kerja Karyawan pada PT. Lion Mentari Airlines Bandara Internasional Soekarno Hatta Cengkareng. Jurnal Ilmu Komputer dan Bisnis, 11(2a), 91-100.

Simanjuntak, F. D., \& Calam, A. (2012). Pengaruh kepemimpinan transformasional dan motivasi kerja terhadap kinerja karyawan PT. PLN (Persero) Cabang Binjai Wilayah Sumatera Utara. Jurnal Saintikom, 11(2), 79-86.

Sofyan, S., Prasada, D., \& Akbar, I. R. (2020). Pengaruh Motivasi, Lingkungan Kerja dan Kepuasan Kerja Terhadap Kinerja Guru SMP/MTs Muhammadiyah Cabang Sawangan.

Suryani, N., \& Pramandari, P. (2016). Pengaruh Kepemimpinan Transformasional Dan Motivasi Kerja Terhadap Kinerja Karyawan. Jurnal Ilmu Manajemen Mahasaraswati, 6(2), 100572. 